\title{
Prices and Health: Identifying the Effects of Nutrition, ExerCise, AND Medication Choices on Blood Pressure
}

\author{
Shih-Neng Chen, Jason F. Shogren, Peter F. Orazem, \\ and Thomas D. Crocker
}

\begin{abstract}
Biomedical studies suggest that a person's behavior matters to health, but these studies usually treat human choice as exogenous. This study shows that individual choices on nutrient intake, exercise, and use of medication are influenced by exogenous food prices, wages, and non-labor income. Using these exogenous variables as instruments for endogenous behavior makes a big difference in the estimated impact of nutrient intake, exercise, and medication on blood pressure. For example, application of instrumental variables methods changes the impact of sodium on blood pressure from positive to negative and significant.
\end{abstract}

Key words: exercise, food prices, health, instrumental variables, measurement error, nutrition.

In his 1993 Nobel Prize speech, economic historian Robert Fogel documented how dramatic improvements in human health and lifespan over the last century have increased labor productivity and economic growth. These health improvements were largely ascribed to better nutrition and to an enhanced ability of consumers to transform nutrition information into desired health states. At the same time, Fogel called for joint use of biomedical and economic techniques of analysis so that the consequences of better nutrition for human well-being can be more deeply probed. The combined techniques would yield insights otherwise unobtainable when relying on one of the disciplines alone.

Fogel's plea for combined techniques rarely has been heeded, either in the biomedicine or in the health economics literature. Biomedical studies adhere strictly to a mind-body dualism

\footnotetext{
Shih-Neng Chen is an associate professor in the Department of Economics at Shih Hsin University, Taiwan; Jason Shogren is the Stroock Distinguished Professor of Natural Resource Conservation and Management and Thomas Crocker is the J.E. Warren Distinguished Professor of Energy and Environment in the Department of Economics and Finance at University of Wyoming; and Peter Orazem is a professor in the Department of Economics at Iowa State University.

The authors thank Wallace Huffman, Peter Berck, Mike Liebman, and two reviewers for their helpful comments. Shogren gratefully acknowledges the funding provided by the U.S. Department of Agriculture/Economic Research Service. Journal Paper No. J-19306 of the Iowa Agriculture and Home Economics Experiment Station, Ames, Iowa, Project No. 0260, and supported by Hatch Act and State of Iowa funds.
}

perspective that sees mental and biochemical processes as separable. This view holds that the conceptual tools of chemistry and physics when applied to the body will ultimately suffice to explain observed associations between nutrition choices and human health outcomes. The possibility that nutrition choices are made conditional on health outcomes is not formally modeled. Instead, epidemiological approaches customarily treat endogenous dietary choices as exogenous. ${ }^{1}$ Consequently, estimates obtained with these approaches of the responses of underlying biological processes to changes in nutrient consumption are biased and not consistent. Most of the economics literature in the health-nutrition area has focused on the willingness of the public to select eating habits consistent with the biomedical findings (e.g., Behrman and Wolfe, Kenkel, and Variyam et al.). By accepting the causal implications of the biomedical model, the economics literature exhibits a curious inconsistency. In particular, a person is viewed as caring about his health state and having the discretion to affect health via choices of what he eats. However, the knowledge base from the biomedical research does not address the role of

\footnotetext{
1 "Research on exogenous causes of hypertension has focused on diet, physical activity, and psychological factors" (Lefant, p. 1605). That is, according to this editorial statement in a prestigious medical journal, biomedicine studies the sources of hypertension without feeling impelled to explain dietary choices, etc.
} 
those endogenous nutrition choices on health outcomes.

Nutrition studies that show how health inputs are simply manifestations of people's choices are limited in number and appear to reside exclusively in the economics literature, for example, Behrman and Deolalikar, Pitt and Rosenzweig, and Strauss. Those few attempts in biomedicine to introduce behavioral considerations do not formally model how individuals' decisions about what they eat depend upon prices and income. Consequently, the estimated health response to a price-induced change in any one nutrient will be an amalgam of the health responses to changes in consumption of all health inputs induced by the original price change.

Though, in principle, laboratory studies of the health consequences of nutrient intake can eliminate the endogeneity issue through experimental controls, extrapolations of laboratory results in the form of dietary recommendations may prove misleading. Nutrient choices, which are constrained by the experimental design, may not reflect the unconstrained choices of consumers. Consequently, recommended changes in the consumption of one nutrient may induce people to alter their consumption of other health inputs as well. The extent to which they choose to do so depends on factors such as preferences, wages, prices, and income (Shogren and Crocker). Thus the everyday health consequences of following the recommendation may differ from the laboratory result.

This article integrates an economic analysis of behavioral dietary choice with an epidemiological analysis of adult blood pressure in a heterogeneous population. Some 50 million Americans have high blood pressure, which increases risk of heart attack, stroke, and renal failure (Joint National Committee). Establishing consistent estimates of the response of blood pressure to eating behaviors is critical for informed health policy interventions. We estimate the signs and parameters for blood pressure responses to changes in personal diet, exercise, and medication regimes, assuming that people can choose these health inputs, and that economic variables such as wages, food prices, and income influence these choices.

The empirical results we obtain by devoting systematic attention to the endogeneity of health inputs and to their measurement error frequently differ in magnitude and occasionally in sign from those reached when the endogeneity and measurement error issues are not addressed. For example, consistent with
Atkinson, Crocker, and Williams, and Midgley et al., we find that sodium appears to have no significant impact on blood pressure when endogeneity and measurement error in health inputs are overlooked. When this endogeneity and measurement error are controlled, higher sodium intake is associated with lower blood pressure. While this is the opposite of what most people expect, it does support a strongly held view within the biomedical literature that the link between sodium intake and health states is inconsistent, at best (see Alderman).

The remainder of this paper is organized as follows. The section on model of health production and diets explains how we have adapted the standard household model of health production to the adult blood pressure and diet question. After a description of the features of the sample of our data, we portray the estimation issues we face in the next section. Empirical results are explained in the subsequent section and finally we conclude the paper.

\section{A Model of Health Production and Diets}

Our empirical model is adapted from the household theory of health production (Becker, Grossman, 1972a, 1972b). In this theoretical framework, a person combines time, human capital, and purchased goods to produce utility from health, leisure and other commodities. The person values the purchased goods (e.g., food, exercise bicycles, medication) because they produce characteristics (e.g., nutrients, deliciousness) necessary for the production of utility. Let

$$
U=U(H, L, Z)
$$

be the individual's weakly separable, wellbehaved utility function, where $H$ is a health state, $L$ is leisure, and $Z$ is a composite of purchased goods which do not contribute to bodily health.

Also define the individual's health function as

$$
H=H\left(N_{1}, N_{2}, \ldots, N_{k}, E, M ; \boldsymbol{\Phi}, \boldsymbol{\mu}\right)
$$

where $N_{i}, i=1, \ldots, k$, is his consumption of nutrient $i, E$ is the exercise time, and $M$ is the "level" of medication consumed. Let $\boldsymbol{\Phi}$ be a vector of exogenous observable personal and environmental attributes (e.g., education and gender) that may affect both $(a)$ his allocative efficiency across health inputs and $(b)$ the marginal contribution any particular input 
makes to his health. Let $\boldsymbol{\mu}$ be a vector of similarly exogenous but unobservable attributes such as genetic ability and health endowments. Expression (2) reflects the pure epidemiological model, in which economic variables like input prices play no role in determining health states; for convenience, we call this the Epi-only model.

We now continue to build the economics into the model. The person maximizes utility subject to expression (2) and a full-income budget constraint:

$$
\begin{aligned}
V & +W(T-L-E) \\
& =\sum_{i=1}^{k} P_{i} N_{i}+P_{\mathrm{z}} Z+P_{\mathrm{M}} M
\end{aligned}
$$

where $V$ is non-labor income, $W$ is market wage, $T$ is total time that can be allocated to leisure, work, or exercise, $P_{i}$ are nutrient shadow prices, $P_{\mathrm{z}}$ is the price of the composite good, and $P_{\mathrm{M}}$ is the price of medication. We presume the person's health practices, including what he eats, contribute neither to his work time nor to his wages. ${ }^{2}$

First-order conditions from constrained maximization frameworks like that above state the person maximizes utility by setting to zero the net benefits of additional consumption of each health input. The utility maximizing health input is the product of the effect of the input upon health and the effect of health upon utility. Reduced-form demand functions for the inputs, characteristics, and commodities have the general form

$$
\begin{aligned}
Q^{*}= & Q^{*}\left(P_{1}, P_{2}, \ldots, P_{k}, P_{\mathrm{z}}, P_{\mathrm{M}},\right. \\
& V, W, T, \boldsymbol{\Phi}, \boldsymbol{\mu})
\end{aligned}
$$

where $Q^{*}=\left\{N_{i}^{*}, E^{*}, M^{*}, Z^{*}, L^{*}\right\}$ is the set of utility-maximizing demands for nutrients, exercise, medication, the composite good, non-health purchased goods, and leisure. Substitution of the optimum choices of nutrients, exercise, and medication from expression (4) into expression (2) yields the reduced-form health function

\footnotetext{
${ }^{2}$ This simplifying assumption allows us to treat time in wage work and wage as exogenous, greatly reducing the complexity of our empirical task. What little evidence exists to justify the simplification says that even in a less-developed country where nutrient intake would plausibly affect job performance, empirical results with the household production framework are similar whether or not formal account is taken of the endogeneity of wage work and wages (see Senauer, Sahn, and Alderman).
}

$$
\begin{aligned}
H^{*}= & H^{*}\left(P_{1}, P_{2}, \ldots, P_{k}, P_{\mathrm{z}}, P_{\mathrm{M}},\right. \\
& V, W, T, \boldsymbol{\Phi}, \boldsymbol{\mu}) .
\end{aligned}
$$

Expression (5) says that the individual chooses his health state, conditional on prices, wages, income, and exogenous tastes and endowments. These factors work their way through to his health state through their impact upon the consumption decisions he makes about health inputs. Health states are endogenous.

Consider, for example, the effect upon observed health, $H^{*}$, of a change in the shadow price, $P_{j}$, of nutrient $j$.

$$
\begin{aligned}
\frac{d H^{*}}{d P_{j}}= & \sum_{i=1}^{k}\left(\frac{\partial H}{\partial N_{i}}\right)\left(\frac{d N_{i}}{d P_{j}}\right)+\left(\frac{\partial H}{\partial E}\right) \\
& \times\left(\frac{d E}{d P_{j}}\right)+\left(\frac{\partial H}{\partial M}\right)\left(\frac{d M}{d P_{j}}\right) .
\end{aligned}
$$

The change, $\mathrm{d} H^{*}$, in optimal health induced by a change in the $j$ th health input price depends upon the relative magnitudes of changes in the consumption of all health inputs $\left(\frac{d N_{i}}{d P_{j}}\right.$, $\frac{d E}{d P_{j}}$, and $\left.\frac{d M}{d P_{j}}\right)$ and the effect of these consumption changes upon health $\left(\frac{\partial H}{\partial N_{i}}, \frac{\partial H}{\partial E}\right.$, and $\left.\frac{\partial H}{\partial M}\right)$. Own and cross-price effects in the demand for health inputs in expression (4), as well as the underlying biological process represented in expression (2), influence the observed health state. Empirical specifications guided by the reduced-form model of expression (5) produce estimates of the total effects of the relative prices of health inputs upon health states. Specifications guided by the structural model captured by expressions (2) and (4) allow biological and economic contributions to health states to be distinguished.

\section{Features of the Sample}

Our sample consists of 1,982 people who participated in the second cycle of the U.S. National Health and Nutrition Examination Survey (NHANES II) between February 1976 and April 1978. NHANES II examined its participants' blood pressures and used questionnaires to acquire information on their medical histories, food consumption in the non-holiday weekday immediately preceding the day of the blood pressure examination, and demographics. NHANES is one of the most comprehensive data sets on health and nutrition available. To the best of our knowledge, this article is the only one that matches any NHANES data to price information. 
We employ six types of variables in our empirical analysis. They are: (1) blood pressure; (2) food consumption; (3) food prices; (4) wage, income, and employment; (5) endogenous non-food health inputs; and (6) health endowments. Below we discuss in turn key features of these variables. Table 1 reports the summary statistics.

During each participant's examination and questionnaire session, NHANES II took readings of that person's sitting and recumbent diastolic and systolic blood pressures. Because systolic blood pressure (SYS) is viewed in the medical literature as the dominant indicator of cardiovascular disease risk (Kannel), we employ its recumbent version in millimeters of mercury at the end of the session as our health

Table 1. Sample Statistics

\begin{tabular}{lrr}
\hline & Mean & $\begin{array}{r}\text { Standard } \\
\text { Deviation }\end{array}$ \\
\hline Endogenous & & \\
$\ln$ (SYS) & 4.85 & 0.17 \\
$\ln$ (FAT) & 4.18 & 0.68 \\
$\ln$ (CALCIUM) & 6.38 & 0.79 \\
$\ln$ (SODIUM) & 7.73 & 0.70 \\
$\ln$ (POTASIUM) & 7.71 & 0.56 \\
$\ln ($ CHOLESTEROL) & 5.52 & 0.93 \\
$\ln$ (VITAMIN C) & 4.17 & 1.26 \\
$\ln$ (RIBOFLAVIN) & 0.40 & 0.69 \\
$\ln$ (FATTY ACIDS) & 3.11 & 0.76 \\
$\ln ($ OLEIC ACIDS) & 3.14 & 0.73 \\
EXERCISE & 1.47 & 0.50 \\
MEDICINE & 0.33 & 0.47 \\
Exogenous & & \\
price indices & & \\
MILK & 75.20 & 9.61 \\
EGGS & 75.29 & 8.11 \\
SUGAR & 107.08 & 9.51 \\
COFFEE & 274.67 & 71.73 \\
COLA & 139.09 & 23.08 \\
MEATS & 550.75 & 82.64 \\
POULTRY & 60.05 & 7.73 \\
FRUIT-VEG & 53.60 & 8.22 \\
CEREALS & 66.91 & 6.18 \\
FATS & 181.74 & 10.82 \\
Other & & \\
HHOLD SIZE & 3.05 & 1.76 \\
$\ln$ (WAGE) & 1.02 & 0.89 \\
$\ln ($ INCOME) & 9.49 & 0.78 \\
AGE & 44.73 & 17.86 \\
MALE & 0.48 & 0.50 \\
EDUCATION & 12.20 & 3.16 \\
\hline
\end{tabular}

Note: Based on a sample of 1982 people residing in the San Jose, Tacoma, Minneapolis-St. Paul, Chicago, New York, Newark, Boston, Pittsburgh, Los Angeles, San Diego, and Honolulu SMSAs between February 1976 through March 1978. measure. In our empirical analysis, we treat this health indicator as measured with random error.

The food consumption information in NHANES II is defined as the consumption of standardized servings per day or per week. We use information on consumption of ten food groups for which independent price information was available. The groups are: whole milk (MILK), eggs (EGGS), sugar (SUGAR), coffee (COFFEE), cola (COLA), mammalian meats (MEATS), poultry (POULTRY), fruits and vegetables (FRUIT-VEG), cereals (CEREALS), and fats and oils (FATS).

NHANES II translated this food consumption information into daily intakes of 17 nutrients. Our work includes nine of those nutrients that our review of the biomedical literature said could alter blood pressure. ${ }^{3}$ These nutrients are: FAT, CALCIUM, POTASSIUM, SODIUM, VITAMIN C, CHOLESTEROL, RIBOFLAVIN, FATTY ACID, and OLEIC ACID.

Our sample size was reduced from 28,000 people of all ages to 1,982 adults because NHANES II reports no food prices. Thus, 1,982 individuals include all those in NHANES II who between 1976 and 1978 resided in one of the 11 SMSAs for which the U.S. Bureau of Labor Statistics (1976-78) reports food prices for our ten food groups. ${ }^{4}$ We used the original retail food price data, deflated to January 1976 dollars. The actual food price data allow us to retain measures of relative price levels across commodities and cities, as required to identify nutrient demands.

Though NHANES II provides information on household income, it says nothing about the individual survey participant's wage, the price of his time. Because individual investments (particularly exercise) involve time as well as money, we required an estimate of the individual's price of time. Wage estimates for NHANES II individuals were generated using the parameters for a wage equation estimated from the 1978 Current Population Survey (CPS). Regressors used in the CPS were also incorporated in the NHANES II survey, providing a basis to extrapolate the

\footnotetext{
${ }^{3}$ These studies include Atkinson, Crocker, and Williams; Bennet and Cameron; Bennet and Newport; Bursztyn; Joint National Committee; MacMahon et al.; McCarron et al.; Pietinen et al.; and Pirkle et al.

${ }^{4}$ The eleven SMSAs are: San Jose, CA; Tacoma, WA; Minneapolis-St. Paul, MN; Chicago, IL; New York, NY; Newark, NJ; Boston, MA; Pittsburgh, PA, Los Angeles-Long Beach, CA; San Diego, CA; and Honolulu, HI
} 
Survey predictions to the NHANES II sample individuals.

Hourly wage estimates (WAGE) were generated via ordinary-least-squares by regressing the natural logarithm of CPS wages (total annual earnings divided by annual work hours) on dummies for industry, occupation, region, education, and age. ${ }^{5}$ Heckman's correction was applied to correct the parameter estimates for possible sample selection from individuals who have chosen not to participate in the labor market. ${ }^{6}$ Thus the survey wage estimates apply to any individual, whether or not they actually held a job at the time of the survey.

The endogenous non-food health inputs registered in NHANES II are limited to the participant's subjective, categorical view of the extent to which he engages in recreational EXERCISE (self-defined as very inactive, moderately active, or very active) and a participant statement as to whether or not he regularly took medication (MEDICINE) for a health condition - any health condition, which could either increase or decrease blood pressure depending on the medicine. EXERCISE is quantified as a 1-3 scale, in which $1=$ very inactive, $2=$ moderately active, and $3=$ very active. MEDICINE is a $0-1$ binary variable, in which 1 means the person takes medication regularly for any health condition; 0 otherwise.

NHANES II incorporates a number of indicators of participants' exogenous health endowments, including age in years (AGE), income (INCOME), gender (MALE $=1)$, education in years (EDUCATION), and number of persons in the household (HHOLD SIZE). Note, however, that this list of health endowments measures on which we do have observations by no means exhausts the possible sources of exogenous variation among participants in their health states. The participant may have known, for example, his upbringing and his genetics, but NHANES II did not gather such information. We address this issue in the next section.

\footnotetext{
${ }^{5}$ The regression included sixty dummy variables: four for industry type, five for occupational type, three for regions, and fortyeight assorted interaction terms among them.

${ }^{6}$ The regressors were four dummies for regions of the country, number of persons in the household, number of children eighteen years or younger, marital status, race with blacks not entered, age in years, education in years, and non-wage income. Detailed results for the work participation and the wage estimates are available from the authors.
}

\section{Estimation Issues}

The estimation issues intrinsic to this paper are clarified by initially considering a benchmark, purely epidemiological model, the Epi-only model, of the blood pressure-health input relationship in which all health inputs are treated as exogenous. The Epi-only estimation presumes that the prices of these inputs play no role in the determination of health states (e.g., Bursztyn). Such a model can be written as a stochastic version of the health function in expression (2):

$$
\begin{aligned}
\ln (\mathrm{SYS})= & \beta_{0}+\beta_{1} N_{1}+\cdots+\beta_{k} N_{k} \\
& +\beta_{\mathrm{E}} E+\beta_{\mathrm{M}} M+\beta_{\Phi} \Phi+v
\end{aligned}
$$

where $v$ is an error term. This specification has at least three inadequacies as a device to study the blood pressure-health input relationship.

First, note that expression (7) does not separately label the vector of exogenous but unobservable health-influential attributes, $\mu$, of expression (2). In (7), these attributes must therefore occupy the error term, $v$. But as expression (4) reveals, the quantity of health inputs a person engages depends upon these exogenous but unobservable attributes, implying that the error term in (7) and the health inputs a person chooses are not independently distributed (Geraci). This problem remains even if one adheres strictly to the mind-body dualism of the biomedical perspective. If exogenous, unobserved biochemical attributes such as genetics drive people to eat what they eat, then the error term and the observed health inputs in (7) would be correlated. While explicitly recognizing in our empirical work that people have some discretion over their health input practices, we also employ a consistent estimation procedure that corrects for this unobserved heterogeneity in biochemical and other attributes.

Second, the nutrient intake terms, $N_{1}, \ldots$, $N_{k}$, of expression (7) may be measured with error. As in numerous nutrient studies (e.g., Huang), by presuming a fixed coefficient, Leontieff-type matrix relating nutrients to foods, nutrient intakes become a simple stochastic function of food intakes.

$$
N_{i}=\sum_{j=1}^{m} a_{i j} F_{j}+\delta_{i}
$$

where $F_{j}$ is consumption of food $j$, and $a_{i j}$ is the amount of nutrient $i$ that food $j$ yields. The random error term, $\delta_{i}$, represents the 
discrepancy between the true magnitude and the unsystematic sources of error (differences in the content of nutrient $i$ across items in particular foods, participants' imperfect food consumption recall) in observations of the intake of nutrient $i$. Measurement error in the $N_{i}$ will lead to inconsistent and biased coefficient estimates in (7).

Note that measurement problems in the $N_{i}$ will also create errors in measures dependent upon $N_{i}$. In this model, the utility from food depends on the nutrient content, such that the nutrient shadow prices can be derived from the food prices by the following formula

$$
\bar{P}_{i}=\sum_{j}\left(\frac{a_{i j} \bar{F}_{j}}{\bar{N}_{i}}\right) P_{j}^{F}
$$

which is derived by taking the expectations of equation (8), dividing by average nutrient intake $\bar{N}_{i}$, and weighting each food quantity by its related price, $P_{j}^{F}$. The term in parentheses is the food $j$ share of nutrient $i$ consumption. Because $N_{i}$ is observed with error, $\bar{P}_{i}$ will measure the true shadow price with error. Equation (9) then represents the first-order approximation to this functional representation:

$$
P_{i}=\sum_{j} \xi_{j} P_{j}^{F}+\varepsilon_{i}
$$

In principle, $\xi_{j}$ could be imposed by estimates of food $j$ 's share of nutrient $i$. These shares, however, would be subject to measurement error because of the errors in observed versus true nutrition, $\delta_{i}$.

Third, the non-food health inputs, EXERCISE and MEDICINE, for which we have data, are measured with error. In particular, perception of what constitutes "active" levels of recreational exercise and "regular" taking of medication may differ across participants in the NHANES II sample.

Both measurement error and endogenous variable problems can be handled by instrumental variable methods. Fuller (pp. 14858) shows that instrumental variable methods result in consistent estimates. Amemiya (pp. 234-42) shows the same for the case of endogenous regressors. Full information methods yield efficient estimates. However, our application requires the use of two-stage estimation because of the mixture of continuous and discrete endogenous regressors in equation (7). Two-step estimators are not efficient. Gujarati suggests using bootstrap methods to generate the correct standard errors in two-step processes.

\section{Empirical Results}

This section reports three sets of estimates. We first provide benchmark Epi-only model estimates for expression (7), the stochastic version of the biochemically motivated health function in expression (2). We then describe two sets of estimates for our alternative worldview in which human discretion has a role in the determination of blood pressure. We provide estimates for the reduced-form health function in expression (5)-the Reduced-form model, and then for the structural system defined by expressions (4) and (2) - the Structural model. This structural system first requires estimation of the equations in the health input demand system in expression (4). The predicted utilitymaximizing values for these health inputs are then inserted into the right-hand side of expression (2). This process was repeated 100 times, sampling from the original data with replacement, to generate bootstrap estimates of the standard errors of coefficients.

\section{Benchmark Epi-Only Blood Pressure Production Function}

The first column of table 2 reports the ordinary-least-squares (OLS) estimates of the benchmark Epi-only model represented by expression (7). ${ }^{7}$ All statistically significant coefficients in table 2 have signs conforming to findings common in the biomedical literature. When the signs in table 2 differ from those predicted by the biomedical literature, the associated coefficients fall well short of statistical significance.

\section{Reduced-Form Blood Pressure Function}

Table 3 reports OLS estimates of the Reducedform health function model consistent with equation (5). The estimation uses food prices directly rather than creating nutrient shadow prices as in expression (9). Food prices will be highly correlated with these shadow prices while not being susceptible to their measurement error problems. ${ }^{8}$

Table 3 demonstrates that systolic blood pressure responds to variations in food prices.

\footnotetext{
${ }^{7}$ A translog form of expression (7) was estimated. A joint test of the significance of its 66 additional terms could not reject the more parsimonious Cobb-Douglas form.

${ }^{8}$ Sources of unobserved health endowment heterogeneity such as genetics and upbringing are assumed to be contemporaneously uncorrelated with food prices, income, and wages, thus implying that the table 3 coefficients are consistent.
} 
Table 2. Blood Pressure Functions $(N=$ 1982)

\begin{tabular}{|c|c|c|}
\hline & $\begin{array}{c}\text { Benchmark } \\
\text { Epi-Only } \\
\text { Model (OLS) }\end{array}$ & $\begin{array}{c}\text { Two-Stage } \\
\text { Structural } \\
\text { Model }\end{array}$ \\
\hline Intercept & $\begin{array}{l}6.18^{* * *} \\
(0.23)^{\mathrm{a}}\end{array}$ & $\begin{array}{l}10.4^{* * *} \\
(2.20)^{\mathrm{b}}\end{array}$ \\
\hline \multicolumn{3}{|l|}{ Nutrient Choices } \\
\hline $\ln (\mathrm{FAT})$ & $\begin{array}{c}-0.0183 \\
(0.02)\end{array}$ & $\begin{array}{c}0.200 \\
(0.554)\end{array}$ \\
\hline $\ln ($ CALCIUM) & $\begin{array}{c}-0.0198^{* * *} \\
(0.007)\end{array}$ & $\begin{array}{c}-0.503^{* * *} \\
(0.146)\end{array}$ \\
\hline $\ln ($ SODIUM) & $\begin{array}{c}0.007 \\
(0.006)\end{array}$ & $\begin{array}{c}-0.360^{* * *} \\
(0.110)\end{array}$ \\
\hline $\ln ($ POTASIUM $)$ & $\begin{array}{c}0.005 \\
(0.010)\end{array}$ & $\begin{array}{c}0.128 \\
(0.181)\end{array}$ \\
\hline $\ln (\mathrm{CHOLESTEROL})$ & $\begin{array}{c}-0.005 \\
(0.004)\end{array}$ & $\begin{array}{c}-0.225^{* * *} \\
(0.085)\end{array}$ \\
\hline $\ln ($ VITAMIN C) & $\begin{array}{c}0.003 \\
(0.003)\end{array}$ & $\begin{array}{c}0.019 \\
(0.044)\end{array}$ \\
\hline $\ln ($ RIBOFLAVIN) & $\begin{array}{c}0.003 \\
(0.008)\end{array}$ & $\begin{array}{l}0.353^{* * *} \\
(0.107)\end{array}$ \\
\hline $\ln$ (FATTY ACIDS) & $\begin{array}{l}0.0295^{* *} \\
(0.015)\end{array}$ & $\begin{array}{c}0.894^{*} \\
(0.504)\end{array}$ \\
\hline ln(OLEIC ACIDS) & $\begin{array}{c}-0.002 \\
(0.017)\end{array}$ & $\begin{array}{c}-0.679^{* *} \\
(0.300)\end{array}$ \\
\hline \multicolumn{3}{|l|}{ Activity Choices } \\
\hline EXERCISE & $\begin{array}{c}-0.013^{* *} \\
(0.006)\end{array}$ & $\begin{array}{c}-0.178^{* * *} \\
(0.034)\end{array}$ \\
\hline MEDICINE & $\begin{array}{c}0.018^{* *} \\
(0.007)\end{array}$ & $\begin{array}{l}0.366^{* * * *} \\
(0.029)\end{array}$ \\
\hline \multicolumn{3}{|l|}{ Demographics } \\
\hline $\ln (\mathrm{AGE})$ & $\begin{array}{c}-0.897^{* * *} \\
(0.128)\end{array}$ & $\begin{array}{c}-0.455 \\
(1.260)\end{array}$ \\
\hline$[\ln (\mathrm{AGE})]^{2}$ & $\begin{array}{l}0.148^{* * *} \\
(0.018)\end{array}$ & $\begin{array}{c}0.072 \\
(0.180)\end{array}$ \\
\hline MALE & $\begin{array}{l}0.050^{\text {*** }} \\
(0.007)\end{array}$ & $\begin{array}{l}0.168^{* * *} \\
(0.059)\end{array}$ \\
\hline $\ln ($ EDUCATION) & $\begin{array}{c}-0.025^{* * *} \\
(0.009)\end{array}$ & $\begin{array}{c}0.034 \\
(0.040)\end{array}$ \\
\hline $\mathrm{R}^{2}$ & 0.31 & 0.33 \\
\hline
\end{tabular}

Note: Dependent variable: natural logarithm of systolic blood pressure. ${ }^{\text {a }}$ Standard errors in parentheses.

${ }^{b}$ Bootstrap standard errors based on 100 replications of the analysis sampled with replacement are reported in parentheses.

${ }^{*}$ Significance at the 0.1 level; ${ }^{* *}$ Significance at the 0.05 level; ${ }^{* * *}$ Significance at the 0.01 level.

Of the food prices included in the regression, only the price of cereals fails to have a statistically significant effect on systolic blood pressure. The price elasticities are small-all are below 0.1 in absolute value. Increases in the prices of whole milk, sugar, coffee, meats, and fats and oils reduce systolic blood pressure, while increases in the prices of eggs, cola, poultry, and fruits/vegetables raise systolic blood pressure.
Table 3. Reduced-Form Blood Pressure Function $(N=$ 1982)

\begin{tabular}{lc}
\hline Intercept & $5.83^{* * *}$ \\
Price Indices & $(0.28)$ \\
MILK & $-0.032^{* *}$ \\
& $(0.013)$ \\
EGGS & $0.0144^{* * *}$ \\
& $(0.004)$ \\
SUGAR & $-0.006^{*}$ \\
& $(0.0037)$ \\
COFFEE & $-0.0007^{* *}$ \\
COLA & $(0.0003)$ \\
& $0.002^{* *}$ \\
MEATS & $(0.001)$ \\
& $-0.0003^{* * *}$ \\
POULTRY & $(0.0001)$ \\
& $0.022^{* * *}$ \\
FRUIT-VEG & $(0.004)$ \\
CEREALS & $0.032^{* * *}$ \\
& $(0.008)$ \\
FATS & 0.003 \\
& $(0.012)$ \\
ln(WAGE) & $-0.013^{* * *}$ \\
& $(0.003)$ \\
ln(INCOME) & -0.002 \\
& $(0.005)$ \\
Demographics & 0.0075 \\
HHOLD SIZE & $(0.005)$ \\
& \\
AGE & 0.0014 \\
AGE & $(0.002)$ \\
& 0.0001 \\
MALE & $(0.001)$ \\
EDUCATION & $0.006^{* * *}$ \\
& $(0.001)$ \\
& $0.049^{* * *}$ \\
& $(0.007)$ \\
& $-0.003^{* * *}$ \\
& $(0.001)$ \\
& 0.34 \\
& \\
& \\
&
\end{tabular}

Note: Dependent variable: natural logarithm of systolic blood pressure Standard errors in parentheses.

*Significance at the 0.1 level; ${ }^{* *}$ Significance at the 0.05 level; *** Significance at the 0.01 level.

These patterns are consistent with dietary choices that, for example, substitute toward poultry when the relative price of meats increases and away from fruits and vegetables when the relative price of fats and oils declines. Variations in food prices change food consumption patterns, altering the sources and perhaps the amounts of nutrient intakes. Changes in food prices may also alter health activities choices such as EXERCISE and MEDICINE, which can modify the variation in health outcomes that could result from 
changing nutrient intake. ${ }^{9}$ All the nutrient and health activity choices in table 2 must be viewed as endogenous in the estimation.

\section{Structural Model Estimates of Health Input Demand Equations}

Now consider the estimates of the Structural model. Expressions (4) and (2) guide the twostage estimation procedure for column 2 in table 2. Expression (4) requires initial estimation of a system of reduced-form demand equations for health inputs so that cross-price substitution effects among these inputs are taken into account. The predicted quantities of nutrient and health activity choices are then used as explanatory variables in estimating expression (2), the structural health function. By applying this two-stage consistent estimator, we guarantee closed-form solutions for the demand equation system, correct for measurement error, and account for the joint impacts of health endowments upon health input decisions and health states.

The explanatory variables in the demand equation system for the nine nutrients, recreational exercise, and medication were those included in table 3. OLS estimates of these health inputs demands were jointly significant from the 1 to $10 \%$ levels. Similar to results reported by Strauss and Thomas, the $\mathrm{R}^{2}$ 's for all of the first-stage health input demand equations were in the 0.10 to 0.20 range, except those for cholesterol and vitamin $\mathrm{C}$ being 0.09 and 0.06 . Table 4 reports these estimates.

Fat and sodium intakes were inversely related to the price of fats and oils. Calcium intakes varied inversely with poultry prices and fruit and vegetable prices, and directly with meat prices and fats and oils prices. Calcium is found in dairy products, which are also sources of protein. Potassium intake and meat prices were positively related. Fruits and vegetables are primary sources of potassium. Except in these instances, the individual effects of food price variation on nutrient intakes were statistically insignificant. Also, food prices were similarly insignificant in ordered probit and probit models explaining recreational exercise and medication demand.

The other exogenous variables had greater statistical influence on health inputs than did food prices. Wages positively influenced potas-

\footnotetext{
${ }^{9}$ Because the utility function in expression (1) is assumed to be weakly separable in its arguments, leisure and non-health good purchases can be treated as predetermined.
}

sium intake and negatively affected recreational exercise and medication. Grossman (1972a) and others have used a pure investment model of health to show that people who earn more are healthier, implying that they demand less medication. Any assignment of cause and effect between potassium and wages must be conjectural but one plausible connection is that more potassium intake over the intervals observed increases health and thereby wages. The negative association between wages and exercise is consistent with the well-known increasing opportunity cost of time as the wage rate increases. At sample means, the implied wage elasticity for exercise is -0.24 , so a $10 \%$ wage increase will induce a $2.4 \%$ reduction in exercise. With the exception of the wage price of time, price elasticities are universally low. The highest, for example, is between calcium intake and fruit and vegetable prices-a $10 \%$ increase in the price of fruit and vegetables causes slightly less than a $1 \%$ decrease in calcium intake. These low price elasticities may reflect the numerous substitution possibilities our system of demand equations allows us to capture.

Though the magnitudes were small $(0.045$ to 0.085$)$, the income elasticities for calcium, sodium, potassium, and vitamin $\mathrm{C}$ were statistically significant. Exercise and medication were not sensitive to income variation. The number of persons in the household was negatively related to sodium and potassium intakes. Consistent with the presence of a household liquidity constraint, medication demand fell with the number of household persons. Except for vitamin $\mathrm{C}$, men demanded more nutrients than did women and they engaged in more recreational exercise. Women took more medication than did men. Other than cholesterol and fatty acids, more educated individuals demanded more of all nutrients and also exercised more. Given that education and wealth are strong correlates, when these nutrients are negative health inputs, the results are consistent with Grossman's (1972b, chap. III) pure consumption model of the demand for health; when they are positive health inputs, the result are consistent with his pure investment model. As age rose, demand for vitamin $\mathrm{C}$, riboflavin, and medication increased while the demand for fats fell.

Taken as a group, the instruments used to identify health input demands performed well. An $F$-test of joint significance of the thirteen instruments (food prices, wages, income, and household size) could reject the null 
Table 4. Structural Estimates of Nutrient and Health Activity Choices $(N=1982)$

\begin{tabular}{|c|c|c|c|c|c|c|}
\hline & FAT $^{\mathrm{a}}$ & CALCIUM $^{\mathrm{a}}$ & SODIUM $^{\mathrm{a}}$ & POTASSIUM $^{\mathrm{a}}$ & CHOLESTEROL $^{\mathrm{a}}$ & VITAMIN C $^{\mathrm{a}}$ \\
\hline Intercept & $\begin{array}{l}5.73^{* * *} \\
(1.28)\end{array}$ & $\begin{array}{l}4.57^{* * *} \\
(1.55)\end{array}$ & $\begin{array}{l}1.08 \times 10^{* * *} \\
(0.14 \times 10)\end{array}$ & $\begin{array}{l}6.59^{* * *} \\
(1.08)\end{array}$ & $\begin{array}{l}5.37^{* * * *} \\
(1.85)\end{array}$ & $\begin{array}{c}0.24 \\
(2.56)\end{array}$ \\
\hline \multicolumn{7}{|l|}{ Price Indexes } \\
\hline MILK & $\begin{array}{r}0.005 \\
(0.06)\end{array}$ & $\begin{array}{c}0.095 \\
(0.07)\end{array}$ & $\begin{array}{c}-0.004 \\
(0.062)\end{array}$ & $\begin{array}{c}0.037 \\
(0.049)\end{array}$ & $\begin{array}{c}0.028 \\
(0.083)\end{array}$ & $\begin{array}{c}0.037 \\
(0.115)\end{array}$ \\
\hline EGGS & $\begin{array}{c}0.006 \\
(0.016)\end{array}$ & $\begin{array}{c}-0.029 \\
(0.019)\end{array}$ & $\begin{array}{c}0.026 \\
(0.017)\end{array}$ & $\begin{array}{r}-0.009 \\
(0.014)\end{array}$ & $\begin{array}{c}-0.014 \\
(0.023)\end{array}$ & $\begin{array}{c}-0.011 \\
(0.032)\end{array}$ \\
\hline SUGAR & $\begin{array}{r}0.0015 \\
(0.017)\end{array}$ & $\begin{array}{c}0.026 \\
(0.021)\end{array}$ & $\begin{array}{c}-0.013 \\
(0.018)\end{array}$ & $\begin{array}{c}0.013 \\
(0.014)\end{array}$ & $\begin{array}{r}0.0002 \\
(0.024)\end{array}$ & $\begin{array}{c}0.016 \\
(0.034)\end{array}$ \\
\hline COFFEE & $\begin{array}{c}-0.001 \\
(0.016)\end{array}$ & $\begin{array}{c}0.002 \\
(0.002)\end{array}$ & $\begin{array}{c}-0.002 \\
(0.002)\end{array}$ & $\begin{array}{c}0.0006 \\
(0.001)\end{array}$ & $\begin{array}{c}-0.001 \\
(0.002)\end{array}$ & $\begin{array}{c}0.003 \\
(0.003)\end{array}$ \\
\hline COLA & $\begin{array}{c}-0.003 \\
(0.006)\end{array}$ & $\begin{array}{c}-0.007 \\
(0.007)\end{array}$ & $\begin{array}{c}-0.001 \\
(0.006)\end{array}$ & $\begin{array}{c}-0.004 \\
(0.005)\end{array}$ & $\begin{array}{c}-0.002 \\
(0.009)\end{array}$ & $\begin{array}{r}-0.003 \\
(0.012)\end{array}$ \\
\hline MEATS & $\begin{array}{r}0.001^{* *} \\
(0.0005)\end{array}$ & $\begin{array}{c}0.001 \\
(0.005)\end{array}$ & $\begin{array}{r}0.001^{* *} \\
(0.0005)\end{array}$ & $\begin{array}{l}0.008^{* * *} \\
(0.0004)\end{array}$ & $\begin{array}{l}0.001 \\
(0.0007)\end{array}$ & $\begin{array}{l}0.001 \\
(0.0009)\end{array}$ \\
\hline POULTRY & $\begin{array}{c}0.003 \\
(0.019)\end{array}$ & $\begin{array}{c}-0.046^{* *} \\
(0.023)\end{array}$ & $\begin{array}{c}0.034^{*} \\
(0.020)\end{array}$ & $\begin{array}{c}-0.019 \\
(0.016)\end{array}$ & $\begin{array}{c}-0.025 \\
(0.027)\end{array}$ & $\begin{array}{c}-0.029 \\
(0.038)\end{array}$ \\
\hline FRUIT-VEG & $\begin{array}{c}0.005 \\
(0.035)\end{array}$ & $\begin{array}{c}-0.087^{* *} \\
(0.043)\end{array}$ & $\begin{array}{c}0.054 \\
(0.038)\end{array}$ & $\begin{array}{c}-0.034 \\
(0.030)\end{array}$ & $\begin{array}{c}-0.021 \\
(0.051)\end{array}$ & $\begin{array}{c}-0.031 \\
(0.071)\end{array}$ \\
\hline CEREALS & $\begin{array}{c}-0.021 \\
(0.054)\end{array}$ & $\begin{array}{c}-0.046 \\
(0.66)\end{array}$ & $\begin{array}{c}-0.007 \\
(0.058)\end{array}$ & $\begin{array}{c}-0.023 \\
(0.046)\end{array}$ & $\begin{array}{c}-0.044 \\
(0.078)\end{array}$ & $\begin{array}{c}-0.010 \\
(0.108)\end{array}$ \\
\hline FATS & $\begin{array}{c}-0.009 \\
(0.012)\end{array}$ & $\begin{array}{r}0.024^{*} \\
(0.014)\end{array}$ & $\begin{array}{c}-0.030^{* *} \\
(0.013)\end{array}$ & $\begin{array}{c}0.007 \\
(0.010)\end{array}$ & $\begin{array}{c}0.012 \\
(0.017)\end{array}$ & $\begin{array}{c}0.010 \\
(0.024)\end{array}$ \\
\hline $\ln (\mathrm{WAGE})$ & $\begin{array}{c}0.032 \\
(0.022)\end{array}$ & $\begin{array}{c}0.004 \\
(0.027)\end{array}$ & $\begin{array}{c}0.006 \\
(0.024)\end{array}$ & $\begin{array}{c}0.034^{*} \\
(0.019)\end{array}$ & $\begin{array}{c}0.047 \\
(0.032)\end{array}$ & $\begin{array}{c}0.049 \\
(0.044)\end{array}$ \\
\hline \multicolumn{7}{|l|}{ Demographics } \\
\hline $\begin{array}{l}\text { HHOLD } \\
\text { SIZE }\end{array}$ & $\begin{array}{c}-0.009 \\
(0.009)\end{array}$ & $\begin{array}{r}-0.017 \\
(0.011)\end{array}$ & $\begin{array}{c}-0.026^{* * *} \\
(0.010)\end{array}$ & $\begin{array}{c}-0.018^{* *} \\
(0.008)\end{array}$ & $\begin{array}{r}-0.004 \\
(0.014)\end{array}$ & $\begin{array}{c}-0.028 \\
(0.019)\end{array}$ \\
\hline $\ln (\mathrm{INCOME})$ & $\begin{array}{c}0.034 \\
(0.021)\end{array}$ & $\begin{array}{r}0.045^{*} \\
(0.026)\end{array}$ & $\begin{array}{l}0.065^{* * *} \\
(0.023)\end{array}$ & $\begin{array}{l}0.044^{* *} \\
(0.018)\end{array}$ & $\begin{array}{c}-0.033 \\
(0.031)\end{array}$ & $\begin{array}{l}0.085^{* *} \\
(0.043)\end{array}$ \\
\hline $\mathrm{AGE}$ & $\begin{array}{c}-0.012^{* *} \\
(0.006)\end{array}$ & $\begin{array}{c}-0.002 \\
(0.007)\end{array}$ & $\begin{array}{c}-0.004 \\
(0.006)\end{array}$ & $\begin{array}{c}-0.004 \\
(0.005)\end{array}$ & $\begin{array}{c}-0.001 \\
(0.008)\end{array}$ & $\begin{array}{c}-0.024^{* *} \\
(0.011)\end{array}$ \\
\hline $\mathrm{AGE}^{2}$ & $\begin{array}{c}0.007 \\
(0.006)\end{array}$ & $\begin{array}{c}0.016^{* *} \\
(0.008)\end{array}$ & $\begin{array}{l}0.00003 \\
(0.007)\end{array}$ & $\begin{array}{c}0.004 \\
(0.005)\end{array}$ & $\begin{array}{c}-0.002 \\
(0.009)\end{array}$ & $\begin{array}{l}0.035^{* * *} \\
(0.013)\end{array}$ \\
\hline MALE & $\begin{array}{l}0.456^{* * *} \\
(0.033)\end{array}$ & $\begin{array}{l}0.374^{* * * *} \\
(0.04)\end{array}$ & $\begin{array}{l}0.422^{* * *} \\
(0.035)\end{array}$ & $\begin{array}{l}0.305^{* * *} \\
(0.028)\end{array}$ & $\begin{array}{l}0.475^{* * * *} \\
(0.047)\end{array}$ & $\begin{array}{c}0.060 \\
(0.065)\end{array}$ \\
\hline EDUCATION & $\begin{array}{l}0.010^{* *} \\
(0.005)\end{array}$ & $\begin{array}{l}0.010^{*} \\
(0.006)\end{array}$ & $\begin{array}{c}0.002 \\
(0.006)\end{array}$ & $\begin{array}{l}0.015^{* * *} \\
(0.004)\end{array}$ & $\begin{array}{c}-0.001 \\
(0.007)\end{array}$ & $\begin{array}{l}0.063^{* * *} \\
(0.010)\end{array}$ \\
\hline$F(13,1964)^{d}$ & $3.75^{* * *}$ & $4.33^{* * *}$ & $2.57^{* * *}$ & $4.14^{* * *}$ & 1.13 & $3.48^{* * *}$ \\
\hline $\mathrm{R}^{2}$ & 0.19 & 0.12 & 0.12 & 0.14 & 0.09 & 0.06 \\
\hline Endowment & $\begin{array}{c}0.063 \\
(0.113)\end{array}$ & $\begin{array}{c}-0.136 \\
(0.131)\end{array}$ & $\begin{array}{c}0.068 \\
(0.117)\end{array}$ & $\begin{array}{c}0.039 \\
(0.093)\end{array}$ & $\begin{array}{r}-0.010 \\
(0.153)\end{array}$ & $\begin{array}{c}0.285 \\
(0.209)\end{array}$ \\
\hline
\end{tabular}

hypothesis that the coefficients were equal to zero in nine of the eleven first-stage equations. In addition, the $F$-test in the exercise equation had a marginal significance level just over the 0.10 threshold. Only in the cholesterol equation do the instruments fail to perform well as a group, suggesting that future work may need to explore the use of other identifiers of cholesterol intake.

As a further check on the presumed endogeneity of the nutrient and activity choices in table 2, a Hausman exogeneity test was applied to the benchmark OLS estimates. With an $F$-value of 7.36, the null hypothesis of exogeneity for all of the health inputs treated jointly in table 2 was easily rejected. This fur- ther amplifies the need for estimation methods that statistically identify health input choices when estimating health functions.

\section{Structural Estimates of the Reduced-form Health Function}

The two-stage results in the second column of table 2 demonstrate that taking account of endogeneity-i.e., assuming that people can choose their health inputs-has great impact upon the inferences one draws about the effects of health inputs on systolic blood pressure. For example, comparison of the results for calcium in columns 1 and 2 of table 2 shows that controlling for endogeneity makes that 
Table 4. Continued

\begin{tabular}{|c|c|c|c|c|c|}
\hline & RIBOFLAVIN $^{\mathrm{a}}$ & $\begin{array}{l}\text { FATTY } \\
\text { ACIDS }^{\text {a }}\end{array}$ & $\begin{array}{l}\text { OLEIC } \\
\text { ACIDS }^{a}\end{array}$ & EXERCISE $^{\mathrm{b}}$ & MEDICINE $^{b}$ \\
\hline Intercept & $\begin{array}{c}1.11 \\
(1.35)\end{array}$ & $\begin{array}{l}5.11^{* * * *} \\
(1.43)\end{array}$ & $\begin{array}{l}4.81^{* * *} \\
(1.38)\end{array}$ & $\begin{array}{c}1.71 \\
(2.63)\end{array}$ & $\begin{array}{c}0.646 \\
(2.80)\end{array}$ \\
\hline \multicolumn{6}{|l|}{ Price Indexes } \\
\hline MILK & $\begin{array}{c}0.031 \\
(0.061)\end{array}$ & $\begin{array}{r}-0.047 \\
(0.064)\end{array}$ & $\begin{array}{c}-0.011 \\
(0.062)\end{array}$ & $\begin{array}{c}0.071 \\
(0.12)\end{array}$ & $\begin{array}{r}0.013 \\
(0.13)\end{array}$ \\
\hline EGGS & $\begin{array}{c}-0.005 \\
(0.017)\end{array}$ & $\begin{array}{c}0.019 \\
(0.018)\end{array}$ & $\begin{array}{c}0.008 \\
(0.017)\end{array}$ & $\begin{array}{r}0.005 \\
(0.03)\end{array}$ & $\begin{array}{c}0.012 \\
(0.04)\end{array}$ \\
\hline SUGAR & $\begin{array}{c}0.011 \\
(0.018)\end{array}$ & $\begin{array}{c}-0.015 \\
(0.019)\end{array}$ & $\begin{array}{c}-0.003 \\
(0.018)\end{array}$ & $\begin{array}{r}0.013 \\
(0.03)\end{array}$ & $\begin{array}{l}0.006 \\
(0.04)\end{array}$ \\
\hline COFFEE & $\begin{array}{c}0.0006 \\
(0.002)\end{array}$ & $\begin{array}{c}-0.003 \\
(0.002)\end{array}$ & $\begin{array}{c}-0.002 \\
(0.002)\end{array}$ & $\begin{array}{c}0.0008 \\
(0.003)\end{array}$ & $\begin{array}{c}0.0000 \\
(0.003)\end{array}$ \\
\hline COLA & $\begin{array}{c}-0.004 \\
(0.006)\end{array}$ & $\begin{array}{c}0.002 \\
(0.007)\end{array}$ & $\begin{array}{c}-0.002 \\
(0.006)\end{array}$ & $\begin{array}{r}-0.010 \\
(0.01)\end{array}$ & $\begin{array}{l}-.004 \\
(0.01)\end{array}$ \\
\hline MEATS & $\begin{array}{c}0.0006 \\
(0.0005)\end{array}$ & $\begin{array}{c}0.001^{* *} \\
(0.0005)\end{array}$ & $\begin{array}{c}0.001^{* *} \\
(0.0005)\end{array}$ & $\begin{array}{c}0.001 \\
(0.001)\end{array}$ & $\begin{array}{r}-0.0001 \\
(0.001)\end{array}$ \\
\hline POULTRY & $\begin{array}{c}-0.009 \\
(0.020)\end{array}$ & $\begin{array}{c}0.012 \\
(0.021)\end{array}$ & $\begin{array}{c}0.003 \\
(0.021)\end{array}$ & $\begin{array}{r}-0.006 \\
(0.04)\end{array}$ & $\begin{array}{r}0.027 \\
(0.04)\end{array}$ \\
\hline FRUIT-VEG & $\begin{array}{c}-0.020 \\
(0.037)\end{array}$ & $\begin{array}{c}0.035 \\
(0.040)\end{array}$ & $\begin{array}{c}0.013 \\
(0.038)\end{array}$ & $\begin{array}{r}-0.032 \\
(0.07)\end{array}$ & $\begin{array}{c}0.012 \\
(0.08)\end{array}$ \\
\hline CEREALS & $\begin{array}{c}-0.027 \\
(0.057)\end{array}$ & $\begin{array}{c}0.025 \\
(0.060)\end{array}$ & $\begin{array}{c}-0.001 \\
(0.058)\end{array}$ & $\begin{array}{c}-0.089 \\
(0.11)\end{array}$ & $\begin{array}{r}-0.054 \\
(0.12)\end{array}$ \\
\hline FATS & $\begin{array}{c}-0.001 \\
(0.012)\end{array}$ & $\begin{array}{c}-0.016 \\
(0.013)\end{array}$ & $\begin{array}{c}-0.011 \\
(0.013)\end{array}$ & $\begin{array}{r}-0.006 \\
(0.02)\end{array}$ & $\begin{array}{r}-0.017 \\
(0.03)\end{array}$ \\
\hline $\ln (\mathrm{WAGE})$ & $\begin{array}{c}0.010 \\
(0.023)\end{array}$ & $\begin{array}{c}0.036 \\
(0.025)\end{array}$ & $\begin{array}{c}0.025 \\
(0.024)\end{array}$ & $\begin{array}{c}-0.111^{* *} \\
(0.045)\end{array}$ & $\begin{array}{c}-0.188^{* * *} \\
(0.05)\end{array}$ \\
\hline \multicolumn{6}{|l|}{ Demographics } \\
\hline HHOLD SIZE & $\begin{array}{c}-0.015 \\
(0.010)\end{array}$ & $\begin{array}{r}-0.010 \\
(0.010)\end{array}$ & $\begin{array}{r}-0.006 \\
(0.010)\end{array}$ & $\begin{array}{r}-0.001 \\
(0.02)\end{array}$ & $\begin{array}{c}-0.044^{* *} \\
(0.02)\end{array}$ \\
\hline $\ln (\mathrm{INCOME})$ & $\begin{array}{c}0.027 \\
(0.023)\end{array}$ & $\begin{array}{c}0.026 \\
(0.024)\end{array}$ & $\begin{array}{c}0.017 \\
(0.023)\end{array}$ & $\begin{array}{r}-0.005 \\
(0.04)\end{array}$ & $\begin{array}{r}0.029 \\
(0.05)\end{array}$ \\
\hline AGE & $\begin{array}{c}-0.022^{* * *} \\
(0.006)\end{array}$ & $\begin{array}{c}-0.012^{* *} \\
(0.006)\end{array}$ & $\begin{array}{r}-0.011^{*} \\
(0.006)\end{array}$ & $\begin{array}{r}0.006 \\
(0.01)\end{array}$ & $\begin{array}{l}0.044^{* * *} \\
(0.01)\end{array}$ \\
\hline $\mathrm{AGE}^{2}$ & $\begin{array}{l}0.020^{* * *} \\
(0.007)\end{array}$ & $\begin{array}{c}0.006 \\
(0.007)\end{array}$ & $\begin{array}{c}0.005 \\
(0.007)\end{array}$ & $\begin{array}{r}-0.006 \\
(0.01)\end{array}$ & $\begin{array}{r}-0.026^{*} \\
(0.014)\end{array}$ \\
\hline MALE & $\begin{array}{l}0.404^{* * *} \\
(0.034)\end{array}$ & $\begin{array}{l}0.501^{* * *} \\
(0.037)\end{array}$ & $\begin{array}{l}0.499^{* * *} \\
(0.035)\end{array}$ & $\begin{array}{l}0.137^{* *} \\
(0.07)\end{array}$ & $\begin{array}{c}-0.275^{* * *} \\
(0.07)\end{array}$ \\
\hline EDUCATION & $\begin{array}{l}0.015^{* * *} \\
(0.005)\end{array}$ & $\begin{array}{c}0.006 \\
(0.006)\end{array}$ & $\begin{array}{c}0.007 \\
(0.006)\end{array}$ & $\begin{array}{l}0.058^{* * *} \\
(0.01)\end{array}$ & $\begin{array}{c}0.010 \\
(0.01)\end{array}$ \\
\hline$F(13,1964)^{d}$ & $2.09^{* *}$ & $3.45^{* * *}$ & $3.57^{* * *}$ & 1.51 & $1.89^{* *}$ \\
\hline $\mathrm{R}^{2}$ & 0.13 & 0.18 & 0.18 & $0.03^{\mathrm{c}}$ & $0.12^{\mathrm{c}}$ \\
\hline ENDOWMENT & $\begin{array}{c}-0.041 \\
(0.114)\end{array}$ & $\begin{array}{c}0.107 \\
(0.125)\end{array}$ & $\begin{array}{c}0.097 \\
(0.121)\end{array}$ & $\begin{array}{c}-0.172^{* *} \\
(0.083)\end{array}$ & $\begin{array}{c}0.175^{* *} \\
(0.078)\end{array}$ \\
\hline
\end{tabular}

${ }^{a}$ OLS. Dependent variable in natural logarithm of nutrient intake.

${ }^{b}$ Probit.

${ }^{\mathrm{c}}$ Pseudo R-square.

${ }^{\mathrm{d}}$ Test of the joint significance of coefficients on prices, income and household size.

Standard errors in parentheses.

${ }^{*}$ Significance at the 0.1 level; ${ }^{* *}$ Significance at the 0.05 level; ${ }^{* * *}$ Significance at the 0.01 level.

nutrient appear to be about twenty-five times more effective in reducing blood pressure than does the estimate assuming that calcium intake is exogenous.

The findings of epidemiological and laboratory studies of purportedly exogenous sodium intake impacts on blood pressure are mixed
(Midgley et al.). Table 2 reproduces this ambiguity, a continuing source of controversy in the medical profession (see, e.g., Greenland, Zuger). Sodium intake has no appreciable impact on blood pressure when it is treated as exogenous. But treating sodium intake as endogenous in column 2 results in a negative and 
significant estimated impact on blood pressure. The open question to which we can provide only a speculative response is why sodium intake has a negative effect on blood pressure. All experts agree that people need at least some salt. But the challenge with changing salt in the diet is that other things change too. The demand system we estimate reflects these multifaceted adjustments. The most recent study of people on the so-called DASH diet, a low-fat diet with more fruits and vegetables, finds that average blood pressure dropped significantly more with the change to low-fat foods relative to any restriction on salt (Sacks et al.). Changing to the DASH diet could affect sodium intake in complicated ways when a person uses salt to compliment (read spice up) what might seem to many to be a bland diet of, say cooked broccoli and cauliflower. Our data is too crude to allow us to test any conjecture about the tastes of specific foods complementing each other. Note that Michael Alderman, an MD at the Albert Einstein College of Medicine recently argued that "[u]nfortunately, few data link sodium intake to health outcomes, and that which is available is inconsistent. Without knowledge of the sum of the multiple effects of a reduced sodium diet, no single universal prescription for sodium intake can be scientifically justified." Our results do not contradict his opinion-more data is better. But our results do suggest this data could be even more helpful if it is examined through the lens of an integrated economic and epidemiology model.

Controlling for the endogeneity of riboflavin, fatty acids, and oleic acids also greatly increases the estimated impact of those nutrients on systolic blood pressure. Riboflavin and fatty acids raise blood pressure while oleic acids moderate blood pressure. When endogenous activity choices are accounted for in the estimation, recreational exercise becomes fourteen times more effective at reducing systolic blood pressure, while taking medicine is associated with increased blood pressure. ${ }^{10}$

The most puzzling result from the twostage estimation is the strong negative effect of cholesterol intake on blood pressure. Curiously, the OLS result also suggested a negative, albeit insignificant relationship. However, because the instruments performed poorly in the first-stage cholesterol equation, the negative effect of cholesterol on blood pressure should be viewed with caution.

\footnotetext{
${ }^{10}$ Recall that the measure includes medication taken for all reasons, not just for blood pressure. Medications taken by this sample may raise blood pressure while alleviating other symptoms.
}

Comparisons of the estimated coefficients for observed exogenous health endowments across the two columns exhibit differences in magnitude and statistical significance but not in sign. Treatment for endogeneity makes age less influential. In both columns, age has a U-shaped effect on systolic blood pressure with the minimum occurring early in the third decade of life. However, blood pressure rises faster with age when other health inputs are treated as exogenous. Men have a larger disadvantage in blood pressure in the two-stage estimates, while the impact of education is only modestly different across the two columns.

\section{Impact of Health Endowments on Nutrient and Activity Choices}

Unobserved exogenous health endowments may affect an individual's demand for health inputs. This effect can be identified following Rosenzweig and Schultz. The residuals from column 2 of table 2 represent those sources of a person's blood pressure that are uncorrelated with the exogenous elements of nutrient intake, health activity, and demographic variables included in the model. These residuals will include the individual's health endowment, $\mu$, as well as an error component orthogonal to health input choices. To capture how $\mu$ affects demand for health inputs, Rosenzweig and Schultz suggest conducting auxiliary regressions of individual nutrient and health activity choices on the residuals. The estimated coefficients can be interpreted as identifying how inherited health traits affect behavioral choices concerning health.

The estimated Rosenzweig-Schultz coefficients, labeled ENDOWMENT, are reported at the bottom of table 4 . The estimated health endowment effects in the nutrient regressions were no greater than and usually much less than their standard errors. Apparently blood pressure health endowments do not influence nutrient demands. They do, however, influence demand for recreational exercise and for medication. People with higher idiosyncratic blood pressure (i.e., those with poorer health endowments) have significantly lower demand for recreational exercise. Those with poorer heath endowments have significantly higher demand for medication.

\section{Summary and Conclusions}

Despite gains in human health over the last century, about one out of every six Americans 
still has high blood pressure. And while biomedical studies suggest that a person's behavior affects this risk, this work often treats human choice as an exogenous input into epidemiological models of risk assessment. By treating as exogenous what is endogenous, these studies generate biased and inconsistent estimates of risk-overestimating the threat to some people, and underestimating it to others. This study addresses this inconsistency by integrating behavior with an epidemiological model to establish consistent estimates of the response of blood pressure to changes in personal diet, exercise, and medication regimes. We assume that people choose these health inputs, and that economic variables such as wages, food prices, and income influence these choices.

Our results suggest that prices, wages, and income matter in choosing nutrients and health activities; prices, wages and income can be effectively used as instruments in identifying endogenous inputs into the production of health; and controlling for endogeneity makes a difference in estimated impacts of nutrient intake on blood pressure-when behavior is endogenous and measurement error is controlled, sodium intake is associated with lower blood pressure.

Our findings reinforce the idea that economic choice and health status are a twoway street: our choices affect our health, our health affects our choices (Auster, Leveson, and Sarachek). This seems obvious enough, and yet it is commonly overlooked by both the man in the street and the scientist at work, who generally think of the social and medical disciplines as separate and assume that combining economics with health science would not alter the core of either. The major player in health policy in the United States, the National Institutes of Health (NIH), now acknowledges that choice and health are jointly determined. With its 1997 strategic plan for the Office of Behavioral and Social Science Research, the NIH pressed for a deeper biobehavioral, interdisciplinary perspective within its institutes. This idea behind this biobehavioral research is to combine insight and tools from the "biomedical, behavioral, and social science disciplines to gain a better understanding of the complex, multifaceted interactions that determine healthy and pathological human functioning" (NIH). Our results herein suggest this push to integrate the behavioral sciences into health research deserves serious support. People and society can gain extra health and wealth by a better understanding of how economics can make good health policy better.

\section{[Received July 2000; final revision received October 2001.]}

\section{References}

Alderman, M.H. "Salt, Blood Pressure, and Human Health." Hypertension 36(November 2000):890-93.

Amemiya, T. Advanced Econometrics. Cambridge, MA: Harvard University Press, 1985.

Atkinson, S., T. Crocker, and D. Williams. "An Application of Some Bayesian Diagnostics to a Study of the Impact of Blood Lead upon Human Blood Pressure." Appl. Stoch. Models Data Anal. 2(March 1986):179-91.

Auster, R., I. Leveson, and D. Sarachek. "The Reduction of Health: An Exploratory Study." J. Human Res. 4(Fall 1969):411-36.

Becker, G. "A Theory of the Allocation of Time." Econ. J. 75(September 1965):493-517.

Behrman, J.R., and A.B. Deolalikar. "Health and Nutrition." Handbook of Development Economics, vol.1. H. Chenery and T.N. Srimivasan, eds., pp. 631-771. Amsterdam: North-Holland, 1988.

Behrman, J.R., and B.J. Wolfe. "How Does Mother's Schooling Affect Families' Health, Nutrition, Medical Care Usage, and Household Sanitation?" J. Econometrics 36(September/October 1987):185-204.

Bennett, C., and C. Cameron. Control Your High Blood Pressure-Without Drugs! Garden City: Doubleday \& Co., Inc, 1984.

Bennett, C., and C. Newport. The Control Your High Blood Pressure Cookbook. Garden City: Doubleday \& Co., Inc, 1987.

Bursztyn, P., ed. Nutrition and Blood Pressure. London: John Libbey \& Co. Press, 1987.

Fogel, R.W. "Economic Growth, Population Theory, and Physiology: The Bearing of Long-Term Processes on the Making of Economic Policy." Amer. Econ. Rev. 84(June 1994):369-95.

Fuller, W.A. Measurement Error Models. New York: John Wiley and Sons, 1987.

Geraci, V. "Identification of Simultaneous Equation Models with Measurement Error." J. Econometrics 4(August 1976):263-83.

Greenland, P. "Editorial: Beating High Blood Pressure with Low-Sodium DASH." New Engl. J. Med. 344 (January 2001):53-55.

Grossman, M. "On the Concept of Health Capital and the Demand for Health."J. Pol. Econ. 80(March-April 1972a):233-55. 
The Demand for Health: A Theoretical and Empirical Investigation. New York, NY: Columbia University Press, 1972b.

Gujarati, D. Basic Econometrics, 3rd ed. New York: McGraw-Hill, 1995.

Hausman, J.A. "Specification Tests in Econometrics." Econometrica 46(November 1978):125171.

Heckman, J. "Sample Selection Bias as a Specification Error." Econometrica 47(January 1979):153-61.

Huang, K.S. "Nutrient Elasticity in a Complete Food Demand System." Amer. J. Agr. Econ. 78(February 1996):21-29.

Joint National Committee on Detection, Evaluation, and Treatment of High Blood Pressure. "Detection, Evaluation, and Treatment of High Blood Pressure." Arch. Internal Med. 153(January 1993):154-83.

Kannel, W.B. "Blood Pressure as a Cardiovascular Risk Factor." J. Amer. Med. Assoc. 275(May 1996):1571-76.

Kenkel, D.S. "Health Behavior, Health Knowledge, and Schooling." J. Pol. Econ. 99(April 1991):287-305.

Lefant, C. "High Blood Pressure: Some Answers, New Questions, Continuing Challenges." $J$. Amer. Med. Assoc. 275(May 1996):1604-06.

MacMahon, S., et al. "Blood Pressure, Stroke, and Coronary Heart Disease. Part 1: Prolonged Differences in Blood Pressure: Prospective Observational Studies Corrected for the Regression Dilation Bias." Lancet 335(March 1990):765-74.

McCarron, D., J. Stanton, H. Henry, and C. Morris. "Assessment of Nutritional Correlates of Blood Pressure." Ann. Internal Med. 98(May 1983):715-19.

Midgley, J.P., A.G. Matthew, C.M.T. Greenwood, and A.G. Logan. "Effect of Reduced Dietary Sodium on Blood Pressure." J. Amer. Med. Assoc. 275(May 1996):1590-97.

National Institutes of Health (NIH). A Strategic Plan for the Office of Behavioral and Social Sciences Research at the National Institutes of Health. Washington, DC, http://www1.od.nih. gov/obssr/stratpl.htm., 1997.
Pietinen, P., E. Vartiainen, R. Seppänen, A. Aro, and P. Puska. "Changes in Diet in Finland from 1972 to 1992: Impact on Coronary Heart Disease." Prev. Med. 25(May-June 1996):243-50.

Pirkle, J., J. Schwartz, J. Landis, and W. Harlan. "The Relationships between Blood Lead Levels and Blood Pressure and its Cardiovascular Risk Implications." Amer. J. Epidem. 121(February 1985):246-58.

Pitt, M., and M. Rosenzweig. "Agricultural Prices, Food Consumption and Health and Productivity of Farmers." Agricultural Household Models: Extensions and Applications. I. Singh, L. Squire, and J. Strauss, eds., pp. 153-82. Baltimore: Johns Hopkins Press, 1984.

Rosenzweig, M., and T. Schultz. "Estimating a Household Production Function: Heterogeneity, the Demand for Health Inputs, and their Effects on Birth Weight." J. Pol. Econ. 91(October 1983):723-46.

Sacks, F., et al. (DASH-Sodium Collaborative Research Group). "Effects on Blood Pressure of Reduced Dietary Sodium and the Dietary Approaches to Stop Hypertension (DASH) Diet." New Engl. J. Med. 344 (January 2001): 3-10.

Senauer, B., D. Sahn, and H. Alderman. "The Effect of the Value of Time on Food Consumption Patterns in Developing Countries." Amer. J. Agr. Econ. 68(November 1986):920-27.

Shogren, J., and T. Crocker. "Risk and its Consequences." J. Envir. Econ. Mgmt. 37(January 1999):44-51.

Strauss, J. "Does Better Nutrition Raise Farm Productivity?" J. Pol. Econ. 94(April 1986):297320.

Strauss, J., and D. Thomas. "Health and Labor Productivity: Sorting Out the Relationships." Paper for the XXII International Conference of Agricultural Economists, Zimbabwe, 1994.

Variyam, J.N., J. Blaylock, B.-H. Lin, K. Ralston, and D. Smallwood. "Mother's Nutrition Knowledge and Children's Dietary Intakes," Amer. J. Agr. Econ. 81(May 1999):373-84.

Zuger, A. "With Dietary Salt, What 'Everyone Knows' is in Dispute." New York Times 9(January 2001). 